\title{
Perspectives on carbon emissions from Canadian forest fires
}

\author{
by B.D. Amiro ${ }^{1}$, M.D. Flannigan ${ }^{1}$, B.J. Stocks ${ }^{2}$ and B.M. Wotton ${ }^{2}$
}

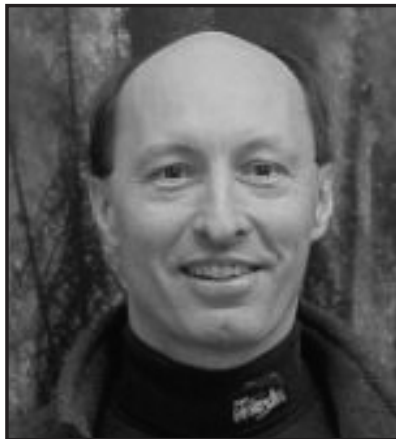

B.D. Amiro

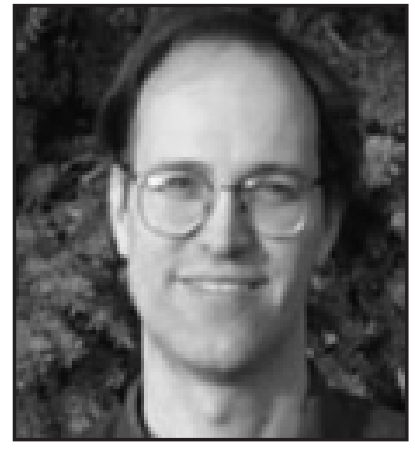

M.D. Flannigan

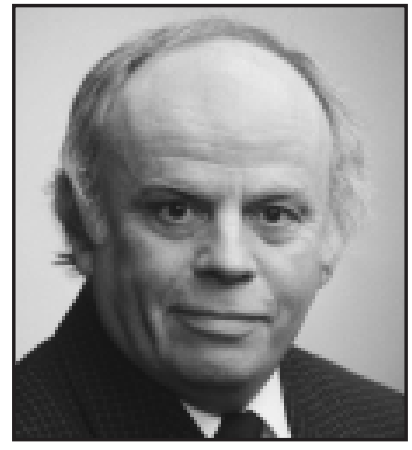

B.J. Stocks

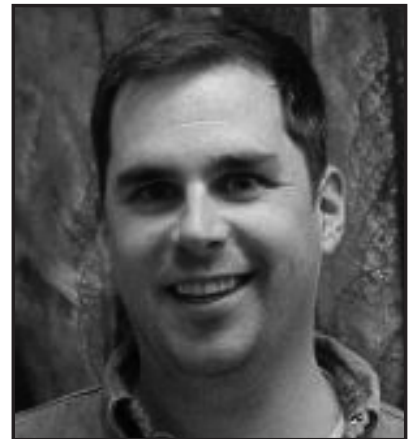

B.M. Wotton

\section{How much carbon is released from Canadian forest fires?}

A recent analysis indicates that Canadian forest fires have released an average of $27 \mathrm{Mt}\left(10^{12} \mathrm{~g}\right)$ of carbon annually over the past four decades (Amiro et al. 2001a). These emissions are caused by direct combustion. About an equal additional amount of carbon may also be lost through decomposition of fire-killed vegetation and a temporary decrease in the forest sink, although this amount is not well quantified. The carbon emissions were calculated based on the size of each fire, the dates over which it burned, and the fuel consumed based on the Canadian Forest Fire Behavior Prediction System (Forestry Canada 1992). The estimates are a product of the Canadian large-fire database, a geographically referenced data set of all fires greater than 200 ha in area, which includes information on the size of each fire and the start date (Stocks et al. 2002). The emissions vary widely among years ranging from 3 to $115 \mathrm{Mt}$ carbon per year (Fig. 1). This is largely caused by the wide interannual variability in area burned, which ranged from 0.3 to 7.5 million ha/year. Across the country, an average of $1.3 \mathrm{~kg}$ of carbon is lost per $\mathrm{m}^{2}$ of burned area, but this varies from about 1 to $2 \mathrm{~kg} \mathrm{C} / \mathrm{m}^{2}$ on average among different ecozones.

\section{How important is this carbon?}

Fires release carbon in the form of carbon dioxide $\left(\mathrm{CO}_{2}\right)$, other gases such as methane and carbon monoxide, and particles (smoke). The mixture of these components depends on the degree of combustion; however, about $90 \%$ of the carbon is released as $\mathrm{CO}_{2}$ (Cofer et al. 1998). From a carbon-emission perspec-

Key words: fire, carbon, climate change, Kyoto Protocol, fire suppression, and biodiversity

${ }^{1}$ Canadian Forest Service, Northern Forestry Centre, 5320 - 122 Street, Edmonton, Alberta T6H 3S5. E-mail: bamiro@nrcan.gc.ca

${ }^{2}$ Canadian Forest Service, Great Lakes Forestry Centre, 1219 Queen Street E., Sault Ste. Marie, Ontario P6A 2E5. tive, we can compare emissions from forest fires to carbon dioxide emissions from fossil fuels in Canada (Fig. 1). It is clear that fossil fuel emissions have been increasing with time whereas fire emissions are more variable, but may also be increasing. These direct fire emissions are significant, especially in high fire years. Fires contribute to greenhouse gases in the atmosphere, such as $\mathrm{CO}_{2}$, methane and nitrogen oxides, which are important drivers of climate warming. Hence, a positive feedback is possible, where increased emissions cause warming, potentially supporting more fires. In addition, there is evidence that smoke promotes positive lightning strikes (positive strikes have more ignition potential than negative strikes) (Lyons et al. 1998), while reducing precipitation (Rosenfeld 1999). Other components of fire emissions have also caused concern. Smoke is always an issue, potentially creating health and transportation hazards. Canadian fires have been implicated in elevated carbon monoxide concentrations in the U.S. (Wotawa and Trainer 2000), and black carbon particles may influence global climates (Hansen et al. 2000, Lavoue et al. 2000, Jacobson 2001). The combination of these issues makes Canadian forest fires a prime target for discussions about decreases in emissions from natural sources.

\section{What might the role of forest fires be in meeting Canadian commitments to the Kyoto Protocol?}

The Kyoto Protocol sets out goals to restrain global warming by limiting carbon emissions from individual countries. For Canada, the goal is to reduce greenhouse gas emissions by $6 \%$ during the 2008 to 2012 commitment period, compared to the 1990 base period (IGBP Terrestrial Carbon Working Group 1998). Negotiations are still underway related to the details of the agreement, but credits for carbon sinks will likely form part of Canada's strategy to achieve the goals. Modelling estimates of forest carbon dynamics for Canada indicate that fires and other disturbances are important drivers of net carbon sequestration (Kurz and Apps 1999, Chen et al. 2000). In fact, the current situation is one where our forests are likely a small carbon source, or at best, a small carbon sink, because of distur- 


\section{Canadian Direct Carbon Emissions}

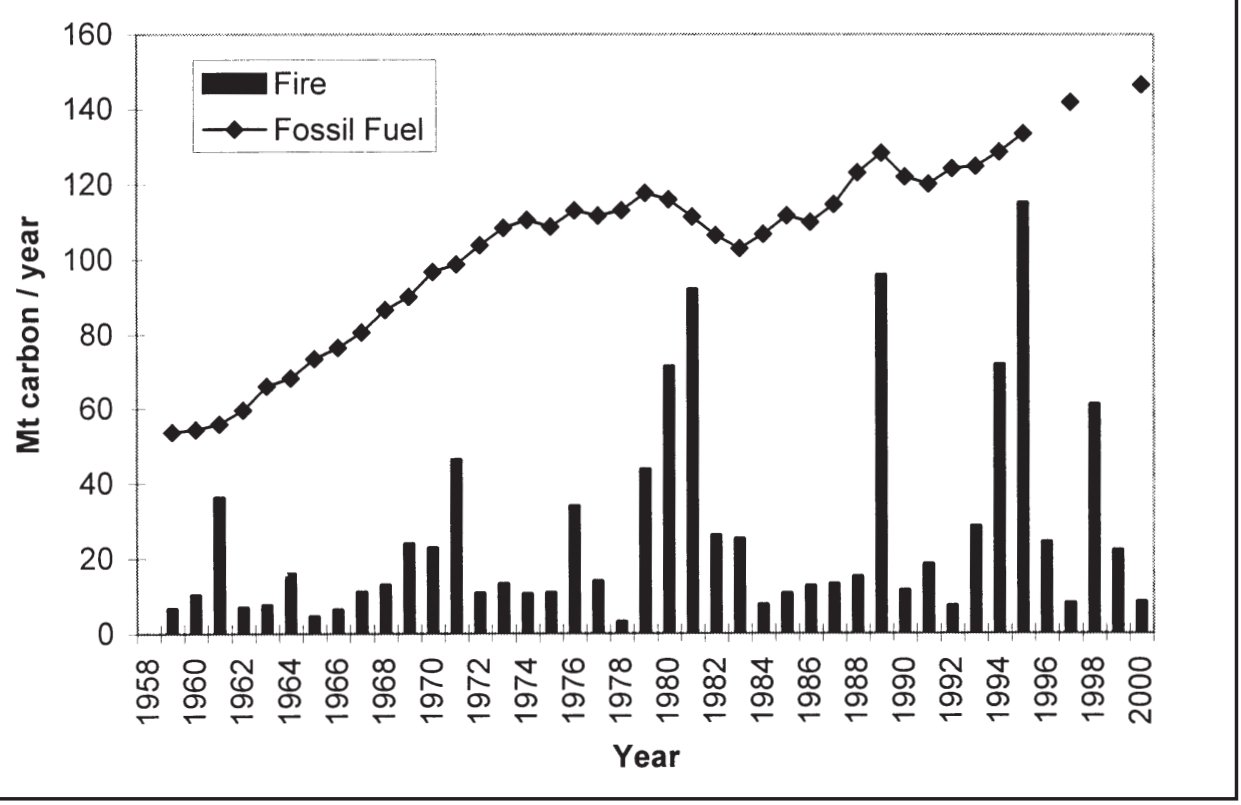

Fig. 1. Canadian carbon emissions from forest fires and fossil fuels. The forest fire emission data are for direct combustion losses (Amiro et al. 2001a). The fossil fuel emission statistics are for carbon dioxide only, obtained from http://www2.ec. gc.ca/Ind/ English/Climate/Tech_Sup/ccsup 01_e.cfm and http://www.nrcan. gc.ca/es/ceo/update.htm. bances over the past few decades. However, the inclusion of many forest-related issues to meet Kyoto Protocol commitments remain to be confirmed, such as how the managed part of the forest is defined and what activities will be included regarding forest carbon sinks. This is an evolving process, which will become better defined before the first commitment period. However, there are future commitment periods, during which different rules could apply.

\section{Can forest fires be mitigated to reduce carbon emissions?}

Forest fire suppression has been an active part of forest management for decades. Despite direct suppression costs of about $\$ 500$ million annually, about two million ha of forested area have burned annually averaged over the past four decades. Most of the area burned is caused by a few large fires, with typically $3 \%$ of the fires burning $97 \%$ of the area (Stocks 1991). Hence, there will always be a few fires that escape initial suppression efforts and grow quickly during extreme fire weather. The allocation of substantially more resources may not be effective at reducing these escaped fires (McAlpine and Hirsch 1999) and may only postpone large fires until severe fire weather occurs. Modification of fuels on the landscape may have some potential to limit the spread of large fires by providing fuel breaks or anchor points to aid suppression. This may be effective to protect communities or specific target areas (Hirsch et al. 2001), but it is difficult to maintain these fuel modifications over large regions. Further, it is virtually impossible to treat the whole Canadian forest. If we created fuel breaks (i.e., areas that would drastically slow the fire spread rate) of about 200-m width to restrict the size of an individual fire to 2000 ha, we would need to treat more than 15 million ha to protect the total Canadian forest (Amiro et al. 2001b). This far exceeds the current annual harvested area of about 1 million ha (CCFM
2001). Hence, our best hope is to optimize protection of specific areas and not focus on the total area burned nationally.

It is important to recognize that fire management is aimed at protecting values at risk, dominated by protecting public health and safety, property, infrastructure, and timber. Carbon by itself is not yet valued in the same context. Indeed, if protection of carbon became a priority and financial budgets remained unchanged, the emphasis on fire protection would need to shift from issues like the wildland/urban interface (where people and property are at risk) to protection of peatlands, which contain vast amounts of carbon. Even if fire management could substantially reduce the area burned, the ecological impact could be unacceptable. The boreal forest comprises about threequarters of the total Canadian forest, and fire is a dominant process. Biodiversity in the boreal forest depends on fire and fire exclusion alters the normal forest renewal process, negatively impacting historical ecosystem function. Canada has international agreements regarding biodiversity (Supply and Services Canada 1995), and protection of carbon by excluding fire would cause conflicts. Given that the current increase in atmospheric greenhouse gases is dominated by fossil fuel emissions (IPCC 2001), efforts to reduce these emissions are likely to be of greater longer-term value in addressing climate change than efforts to further reduce fire emissions, especially as the latter could jeopardize biodiversity and ecological integrity.

\section{What is the outlook for fire in the future?}

Some of the largest annual carbon emissions from forest fires in the last four decades occurred in the last half of this period. Further, there was more fire during the past four decades compared to the previous four (Podur et al. 2002). Predictions from climate models suggest that weather will be more conducive to fire in the future because of warmer temperatures and 
drier conditions in the western part of the boreal forest (Flannigan et al. 1998). Hence, it is likely that carbon emissions from fire will be larger in future Kyoto Protocol commitment periods than in past base periods, recognizing that fire occurrence is highly variable among years. Most of the area burned in Canada is by lightning-caused fires (Stocks et al. 2002). Future population growth into forest areas may increase humancaused fires, but also will provide better access for forest protection. However, this will increase the demand for fire management resources, especially when lives and property are in jeopardy. Our forests will become more fragmented by towns, industrial operations and transportation corridors. Most of this fragmentation has little impact on fire growth during severe weather conditions, when a fire can jump obstacles of several hundred metres. Perhaps the only future activity that will decrease fire is the change of forest fuel types to less flammable ones. Changes in land use could reduce forest areas, and, in some parts of Canada, forest conversion from conifers to deciduous species will slow fire growth. These land use changes themselves would have large impacts on carbon sequestration, and would need to be considered as part of the national carbon balance.

The bottom line is that fire will continue to be part of the Canadian forest and will likely increase if current estimations of future climate change prove accurate (Stocks et al. 1998, Flannigan et al. 2001). This is a natural process in the boreal forest, and our forests depend on it. Although forest fire carbon emissions are significant, their reduction may not be economically feasible and definitely not ecologically desirable.

\section{References}

Amiro, B.D., J.B. Todd, B.M. Wotton, K.A. Logan, M.D. Flannigan, B.J. Stocks, J.A. Mason, D.L. Martell and K.G. Hirsch. 2001a. Direct carbon emissions from Canadian forest fires, 1959 to 1999. Can. J. For. Res. 31: 512-525.

Amiro, B.D., B.J. Stocks, M.E. Alexander, M.D. Flannigan and B.M. Wotton. 2001b. Fire, climate change, carbon and fuel management in the Canadian boreal forest. Int. J. Wildland Fire 10: 405-413.

Canadian Council of Forest Ministers (CCFM). 2001. Compendium of Canadian Forestry Statistics. Natural Resources Canada, Ottawa, ON. (http://nfdp.ccfm.org)

Chen, J.M., W. Chen, J. Liu and J. Cihlar. 2000. Annual carbon balance of Canada's forests during 1895-1996. Global Biogeochem. Cycles 14: 839-850.

Cofer, W.R. III, E.L. Winstead, B.J. Stocks, J.G. Goldammer and D.R. Cahoon. 1998. Crown fire emissions of $\mathrm{CO}_{2}, \mathrm{CO}, \mathrm{H}_{2}, \mathrm{CH}_{4}$, and TNMHC from a dense jack pine boreal forest fire. Geophys. Res. Lett. 25: 3919-3922.

Flannigan, M.D., Y. Bergeron, O. Engelmark and B.M. Wotton. 1998. Future wildfire in circumboreal forests in relation to global warming. J. Veg. Sci. 9: 469-476.

Flannigan, M., I. Campbell, M. Wotton, C. Carcaillet, P. Richard and Y. Bergeron. 2001. Future fire in Canada's boreal forest: paleoecology results and general circulation model - regional climate model simulations. Can. J. For. Res. 31: 854-864.
Forestry Canada. 1992. Development and structure of the Canadian forest fire behavior prediction system. Inf. Rep. ST-X-3. Canadian Forest Service, Ottawa, ON.

Hansen, J., M. Sato, R. Ruedy, A. Lacis and V. Oinas. 2000. Global warming in the twenty-first century: an alternative scenario. Proc. Natl. Acad. Sci. USA 97: 9875-9880.

Hirsch, K., V. Kafka, C. Tymstra, R. McAlpine, B. Hawkes, H. Stegehuis, S. Quintillio, S. Gauthier and K. Peck. 2001. Fire-smart forest management: a pragmatic approach to sustainable forest management in fire-dominated ecosystems. For. Chron. 77(2): 357-363. IGBP Terrestrial Carbon Working Group. 1998. The terrestrial carbon cycle; implications for the Kyoto protocol. Science 280: 1393-1394.

Intergovernmental Panel on Climate Change (IPCC). 2001. Climatic Change 2001: The scientific basis. Contributions of Working Group I to the Third Assessment Report. Available on-line at: http://www.grida.no/climate/ipcc_tar/.

Jacobson, M.Z. 2001. Strong radiative heating due to the mixing state of black carbon in atmospheric aerosols. Nature 409: 695-607.

Kurz, W.A. and M.J. Apps. 1999. A 70-year retrospective analysis of carbon fluxes in the Canadian forest sector. Ecol. Appl. 9: 526-547. Lavoue, D., C. Liousse, H. Cachier, B.J. Stocks and J.G. Goldammer. 2000. Modeling of carbonaceous particles by boreal and temperate wildfires at northern latitudes. J. Geophys. Res. 105: 26 871-26 890.

Lyons, W.A., T.E. Nelson, E.R. Williams, J.A. Cramer and T.R. Turner. 1998. Enhanced positive cloud-to-ground lightning in thunderstorms ingesting smoke from fires. Science 282: 77-80.

McAlpine, R.S. and K.G. Hirsch. 1999. An overview of LEOPARDS: the level of protection analysis system. For. Chron. 75(4): 615-621. Podur, J., D.L. Martell and K. Knight. 2002. Statistical quality control analysis of forest fire activity in Canada. Can. J. For. Res. 32: 195-205.

Rosenfeld, D. 1999. TRMM observed first direct evidence of smoke from forest fires inhibiting rainfall. Geophys. Res. Lett. 26: 3105-3108. Stocks, B.J. 1991. The extent and impact of forest fires in northern circumpolar countries. In J.S. Levine (ed.). Global Biomass Burning. Atmospheric, Climatic and Biospheric Implications. MIT Press, Cambridge, MA.

Stocks, B.J., M.A. Fosberg, T.J. Lynham, L. Mearns, B.M. Wotton, Q. Yang, J-Z. Lin, K. Lawrence, G.R. Hartley, J.A. Mason and D.W. McKenney. 1998. Climate change and forest fire potential in Russian and Canadian boreal forests. Climatic Change 38: 1-13. Stocks, B.J., J.A. Mason, J.B. Todd, E.M. Bosch, B.M. Wotton, B.D. Amiro, M.D. Flannigan, K.G. Hirsch, K.A. Logan, D.L. Martell and W.R. Skinner. 2002. Large forest fires in Canada, 1959-1997. J. Geophys. Res. (in press).

Supply and Services Canada. 1995. Canadian Biodiversity Strategy, Canada's Response to the Convention on Biological Diversity. Biodiversity Convention Office, Environment Canada, Hull, Quebec. (http://www.bco.ec.gc.ca/DocumentPublications_e.cfm). Wotawa, G. and M. Trainer. 2000. The influence of Canadian forest fires on pollutant concentrations in the United States. Science 288: 324-328. 